\title{
Mechanical Performance and Thermo-Physical Properties of Cement Mortar Incorporating Hybrid Slags
}

\author{
Mahad Baawain \\ msab@squ.edu.om \\ Department of Civil and Architectural Engineering, Sultan Qaboos University, Muscat, Oman \\ Hamada Shoukry \\ aboshoukry2020@gmail.com \\ Housing and Building National Research Center (HBRC), Building Physics Institute, Cairo, Egypt \\ Khalifa Al-Jabri \\ aljabri@squ.edu.om \\ Department of Civil and Architectural Engineering, Sultan Qaboos University, Muscat, Oman
}

\begin{abstract}
Owing to the growing environmental pressure to reduce waste and pollution, the effective utilization of industrial solid wastes in construction applications has gained notable attention. This study investigates the mechanical and thermal properties of cement mortars incorporating two types of waste slags. Ferrochrome $(\mathrm{FeCr})$ slag aggregate was used as a replacement for sand at the ratios of 25, 50, 75 and 100 wt. \%. Ground granulated blast furnace slag (GGBS) has been used as a partial replacement of cement at the ratio of 25 wt. \%. Compressive strength, permeable voids content and thermal conductivity tests have been conducted after 28 days of curing. The microstructure characteristics have been investigated by scanning electron microscope (SEM) equipped with energy dispersive analytical x-ray unit (EDAX). The experimental results revealed that $\mathrm{FeCr}$ waste aggregates could satisfactorily replace for natural fine sand in cement mortars up to 25 wt. \% without a remarkable degradation of the compressive strength. Furthermore, Increasing replacement ratios of $\mathrm{FeCr}$ aggregates over 25 wt. \% have resulted in noticeable decrease in thermal conductivity and an increase in the permeable voids content of cement mortars. The integration of GGBS with $\mathrm{FeCr}$ aggregates leads to enhanced compressive strength, reduced voids content and contribute to improved microstructure. The developed mortars with comparatively improved thermal resistance can be recommended for several structural and non-structural applications especially in hot weather regions.
\end{abstract}

Keywords: Ferrochrome slag; Blast furnace slag; Compressive strength; Thermal conductivity; Microstructure

\section{INTRODUCTION}

The utilization of industrial solid waste materials as aggregates in concrete structures has become of great importance in terms of saving landfill space and reducing the consumption and demand for extraction of natural aggregates (Rao \& Prasad, 2002; Taha \& Nounu, 2008; Borhan, 2012). Various types of waste metallurgical slags like steel slag (Nadeem \& Pofale, 2012), copper slag (Al-Jabri et al., 2009), ferronickel (FeNi) slag (Saha \& Sarker, 2017) and recently ferrochrome (FeCr) slag (Al-Jabri et al., 
2018a) have been utilized for fine and coarse aggregates replacements in the production of cement mortar and concrete for various construction applications. Nadeem and Pofale (2012) investigated the use of granular slag as a partial replacement of natural sand in masonry and plastering applications. In this study, cement mortars in various (cement : sand) proportions of 1:3, 1:4, 1:5 and 1:6 by volume were prepared with granular slag replacing 25, 50, 75 and 100 wt.\% of sand. The compressive strength increased with increasing the replacement level up to $75 \mathrm{wt}$. $\%$. An enhancement by about $15 \%$ has been attained relative to the ordinary mortar. An experimental study conducted by Al-Jabri et al. (2011) in which various mortar and concrete mixtures were prepared with different proportions of copper slag ranging from $0 \%$ to $100 \%$ as fine aggregates replacement. The results obtained for cement mortars revealed that all mixtures with different copper slag proportions achieved comparable or higher compressive strength than that of the control mixture. The results obtained for concrete indicated that the substitution of up to $40-50 \%$ copper slag as a sand replacement yielded comparable strength to that of the control mixture. Increasing copper slag over $50 \%$ resulted in strength reduction. The mechanical performance of cement mortar incorporating 25, 50, 75 and $100 \mathrm{wt}$ \% of FeNi slag as a replacement of natural sand has been studied by (Saha \& Sarker, 2017). The compressive strength of the hardened mortars increased with the increase of FNS up to $50 \%$ and then declined with further increase of FNS. The study also revealed that the use of fly ash as $30 \%$ cement replacement together with FNS as replacement of sand decreased the strength of hardened mortars. Ferrochrome $(\mathrm{FeCr})$ slag is a by-product from the production of ferrochrome.

The production of 1 ton of $\mathrm{FeCr}$ alloys yields about 1.1 to 1.6 ton of slag (Niemela \& Kauppi, 2007). In Oman, there are two $\mathrm{FeCr}$ plants producing about $355,000 \mathrm{t}$ of FeCr slag annually Al-(Jabri, 2018a). The majority of this by-product is not reused in an effective manner and is currently being dumped. Dumping of $\mathrm{FeCr}$ slag in the landfills induces environmental problems in terms of the risk of leaching of hazardous elements like Cr (VI) causing contamination of the soil and ground water. Panda et al. (2013) studied the properties of normal and high-strength concrete made with $\mathrm{FeCr}$ slag as an alternative for aggregate. The results indicated that replacement of fine aggregate with FeCr slag up to $75 \%$ has improved the strength of concrete compared with conventional concrete. The influence of elevated temperature on concrete incorporating $50 \mathrm{wt} . \% \mathrm{FeNi}$ slag as sand replacement and 30\% fly ash as cement replacement has been recently studied by (Saha \& Sarker, 2019), the use of 30\% fly ash showed significant improvement in residual compressive strengths of all the mixtures for exposure up to $600^{\circ} \mathrm{C}$. Although, the use of supplementary cementitious materials (SCMs) like silica fume (SF), Fly ash (FA), Ground granulated blast-furnace slag (GGBS), metakaolin (MK), etc., was proved to be very helpful in improving physical, mechanical and microstructural properties of conventional concrete; in addition, the use of SCMs in the production of blended cement can reduce carbon dioxide emissions by approximately $22 \%$ and improve sustainability in construction (Flower \& Sanjayan, 2007), few studies investigated the influence of SCMs on properties of cement mortar and concrete containing high amounts of recycled waste slag aggregates. The aim of this study is to investigate the combined effects of $\mathrm{FeCr}$ slag fine aggregates and GGBS (a by-product of steel making industry) as partial replacement for cement on the properties of cement mortar. 


\section{EXPERIMENTAL DETAILS}

\subsection{Materials}

The cement used in this study was ordinary Portland cement, OPC (CEM I: 42.5 $\mathrm{N})$. Two types of slags have been used in this study including FeCr and GGBS slags. FeCr slag granules were collected from the plants of ferrochrome industry, situated in Al Tamman Indsil Company (ATIC), Sohar city, Oman. GGBS is a byproduct of iron and steel manufacturing; it is also locally available in Oman. The chemical compositions of both FeCr and GGBS are demonstrated in table (1). The type of sand used is natural siliceous. The specific gravity of $\mathrm{FeCr}$ is (2.97) which is slightly higher than that of the sand (2.77). The FeCr grains are angular in shape; while, the sand grains are semirounded. The grain size distribution for the sand, FeCr-slag aggregate (as received) and their combinations in various proportions along with the lower and upper acceptable limits of grading according to ASTM C33 is presented in Fig. 1. It can be seen that the sand possessed the optimum gradation. The FeCr grading curve has exceeded the upper limit of ASTM C33; in addition, the grading is curve is approximately flat especially in the mid-size range, this indicates that the grains are not well-graded; i.e., they can be prone to segregation during mixing. The combination of $\mathrm{FeCr}$ with natural sand has relatively improved the gradation. The replacement of sand by $25 \% \mathrm{FeCr}$ possessed a grading comparable to that of the natural fine sand.

Table 1: Chemical compositions of used slags (mass, \%)

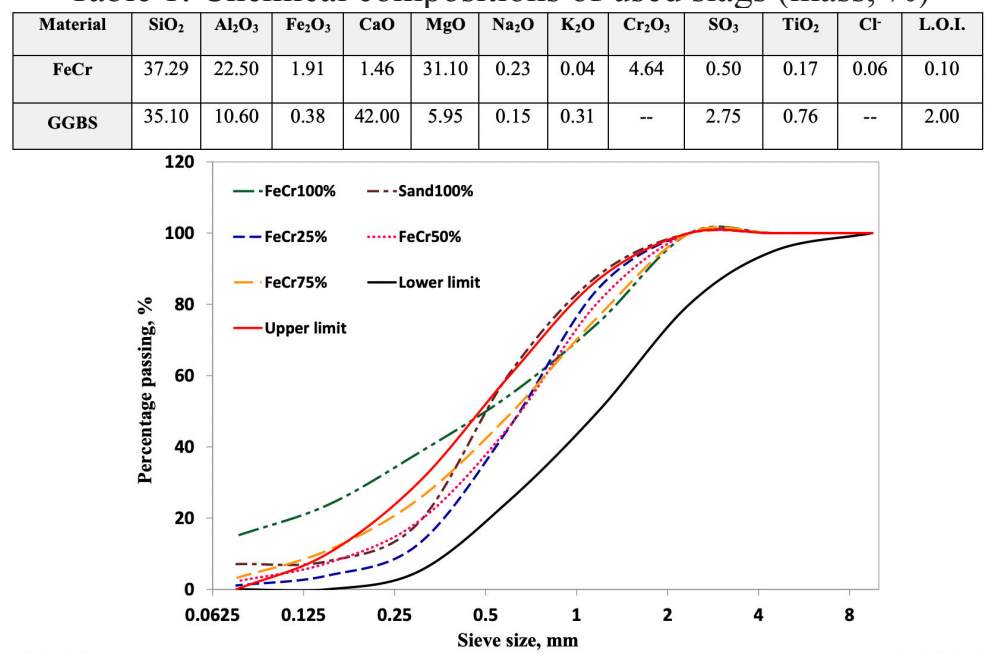

Figure 1: Gradation of sand, FeCr slag and their combinations

\subsection{Samples preparation, identification and testing}

The mortar samples were prepared using binder-sand ratio of $1: 2.75$. Fine sand was replaced with FeCr-slag aggregates at the ratios of 0, 25, 50, 75 and 100 wt. \%. These mixtures were termed as (FeCr0, FeCr25, FeCr50, FeCr75 and FeCr100) respectively. Two groups of samples were prepared using different binders; a group made of OPC and the other made of $25 \mathrm{wt}$. \% GGBS blended-OPC. The GGBS replacement ratio of $25 \mathrm{wt}$. $\%$ was proved to be the optimum by (Oner \& Akyuz, 2007). The blended mortars were prepared using the water of standard consistency in order to attain a constant workability 
degree among different samples. The compressive strength and volume of permeable voids tests were conducted on $50 \mathrm{~mm}$ cube samples at the age of $28 \mathrm{~d}$ in accordance with ASTM C109 and ASTM C642 respectively. Thermal properties analyzer (model: KD2 Pro) was used to evaluate the thermal conductivity of $50 \mathrm{~mm}$ cube dried samples in accordance with ASTM D 5334. The analytical scanning electron microscope, (JEOL JSM-7500F) equipped with EDAX unit for phase analysis was used to examine the microstructural characteristics of the freshly fractured samples.

\section{RESULTS AND DISCUSSION}

\subsection{Compressive strength}

Figure 2 shows the variations in compressive strength of the mortars incorporating various percentages of $\mathrm{FeCr}$ fine aggregates prepared with plain and GGBS-blended cements at the age of 28 day of curing. The mortar incorporating 25 wt. \% of FeCr slag aggregates showed slight insignificant decrement in strength by about $5.70 \%$; whilst, the compressive strength considerably decreases by $23.74,28$ and $41.54 \%$ for the use of $\mathrm{FeCr}$ aggregates at higher percentages 50, 75 and $100 \mathrm{wt} ., \%$ respectively. This is attributed to the variation in grading characteristics of Fine sand and $\mathrm{FeCr}$ slag aggregates. Based on the grading analyses, the fine sand exhibited better grain size distribution than $\mathrm{FeCr}$ slag, which showed lesser proportion of finer aggregates passing $1.18 \mathrm{~mm}$. This is in line with previous studies reported that the use of slag with poor grading inversely affects strength (Saha et al., 2019). The grading that contains small percentages of aggregates in the mid-size range negatively affects the particle packing quality and result in the creation of permeable voids inside the structure. As it was expected, the use of GGBS as a SCM replacing $25 \mathrm{wt}$ \% of OPC has satisfactorily compensated for the loss in compressive strength. The $\mathrm{FeCr} 25$ mortar attained a gain of strength by $10 \%$ and exceeded the compressive strength of the reference mortar made with natural sand and without GGBS. The maximum enhancement caused by GGBS incorporation is obtained for the mortar containing 50 wt. \% FeCr slag aggregates; i.e., $\mathrm{FeCr} 50$ mixture has retrieved about 19\% of the loss of strength relative to the reference ordinary mortar. The pozzolanic activity of GGBS explains the reason of enhanced strength. GGBS is classified as one of the active pozzolanic materials which consumes $\mathrm{Ca}(\mathrm{OH})_{2}$ crystals liberated during cement hydration and creates additional cementing calcium silicate phase $(\mathrm{CSH})$ and results in refining the pore structure and providing compact microstructure (Oner \& Akyuz, 2007).

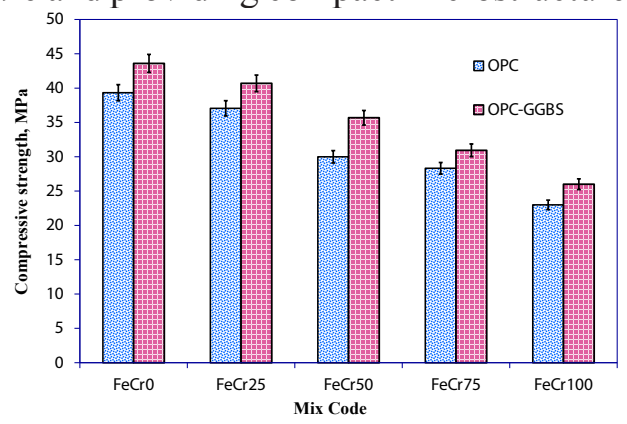

Figure 2: Compressive strengths of mortars containing various amounts of $\mathrm{FeCr}$ aggregates prepared with OPC and GGBS-blended OPC binders at the age of 28 day of curing 


\subsection{Volume of permeable voids}

Figure 3 presents the permeable voids content (vol. \%) for the mortars incorporating various percentages of $\mathrm{FeCr}$ slag aggregates prepared with plain and GGBS-blended cements at the age of 28 day of curing. The remarkable increase of volume of permeable voids (VPV) with increasing $\mathrm{FeCr}$ slag aggregates is consistent with the reduction in compressive strength. The VPV has been increased by about 8, 33.6, 40 and $49 \%$ relative to the reference mortar with the inclusion of $25,50,75$ and 100 wt. $\% \mathrm{FeCr}$ slag aggregates respectively. The increase of VPV points to the poor packing of $\mathrm{FeCr}$ grains inside mortar structure as compared with fine sand. Due to its ultrafine size and high pozzolanic activity, GGBS has considerably reduced VPV for all of $\mathrm{FeCr}$ slagblended mortars by improving the physical packing; furthermore, the additional CSH produced by its pozzolanic reaction gets deposited in the inter-grain space and results in denser microstructure (Babu \& Kumar, 2000). Although GGBS has relatively reduced VPV of the FeCr slag blended mortars, the mixtures that containing high percentages 50,75 and 100 wt. \% of $\mathrm{FeCr}$ recorded permeable voids contents higher than that of the reference mortar which indicates that there is still void spaces not filled with any hydration products.

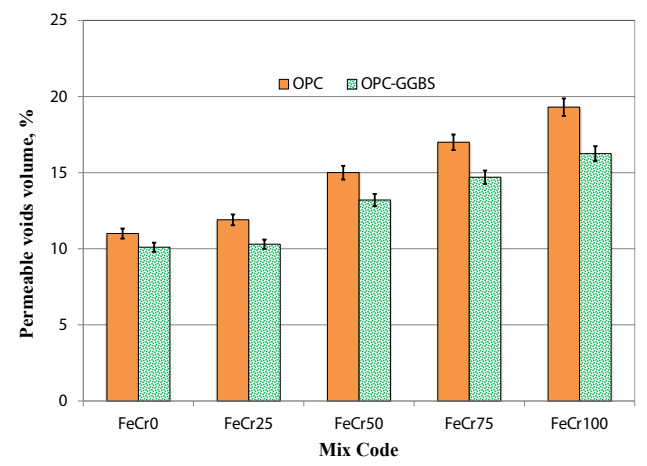

Figure 3: Volume of permeable voids of mortars containing various amounts of $\mathrm{FeCr}$ aggregates prepared with OPC and GGBS-blended OPC binders at the age of 28 day of curing

\subsection{Thermal conductivity}

Figure 4 presents the variation in thermal conductivity of the developed mortars containing $\mathrm{FeCr}$ and GGBS hybrid slags. It can be seen that the thermal conductivity decreases with increasing FeCr slag aggregates in the mortar. The thermal conductivity coefficients have been decreased by about 2.9, 7, 10.6 and $15.5 \%$ for the mortars incorporating $25,50,75$ and $100 \mathrm{Wt}$. \% of $\mathrm{FeCr}$ respectively as compared with the reference mortar. This is assigned to the increase of the voids content and the decrease of the bulk densities of the FeCr slag-blended mortars. These results are in line with findings of a previous study on the use of waste glass as sand replacement (Sikora et al., 2017). Due to its very low thermal conductivity, the static air entrapped in the voids between aggregates caused by the poor packing is responsible for the reduced conductivity coefficients (Krishnamoorthy \& Zujip, 2013). The use of GGBS generally increases the thermal conductivity coefficients of the mortars with and without $\mathrm{FeCr}$ slag aggregates; 
however, the maximum increase was found for the mortar made with fine sand (i.e., without $\mathrm{FeCr}$ ). The increase of thermal conductivity is attributed to the improvement in the physical packing and the relative compactness of the microstructure achieved by incorporating GGBS. The compactness of solid structures facilitates the heat flow by conduction; therefore, increases thermal diffusivity and hence thermal conductivity (AlJabri \& Shoukry, 2018b). The pozzolanic reaction induced by GGBS and the produced $\mathrm{CSH}$ affects the porosity of blended mortar and may alter the size, distribution, shape, and connectivity of the pores; this is the reason behind the considerable variation in the thermal conductivity attained upon the loading of GGBS (Gori \& Corasaniti, 2014).

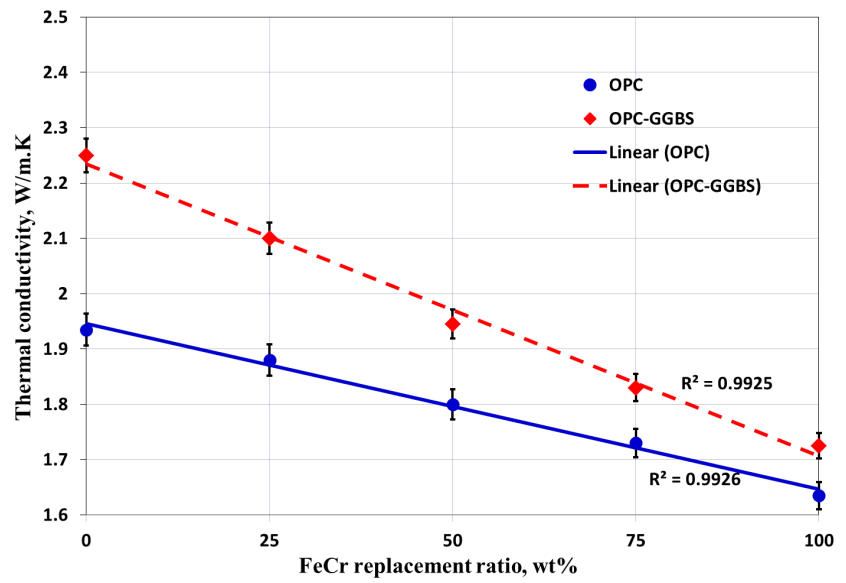

Figure 4: Variations in thermal conductivity of mortars containing various amounts of $\mathrm{FeCr}$ aggregates prepared with OPC and GGBS-blended OPC binders at the age of 28 day of curing.

\subsection{Microstructure characteristics}

SEM investigation was conducted to provide visual evidence of the change in microstructure characteristics responsible for the variation in the mechanical and thermal properties of the mortars incorporating hybrid slags. Figs. 5 and 6 Present SEM micrographs and EDAX spectra for the mortars incorporating 0 and $25 \mathrm{wt}$. \% of FeCr slag aggregates made of plain and GGBS-blended cements. The SEM in Fig. 5(a) displays the most common hydration products of OPC including gel-like $\mathrm{CSH}$ and $\mathrm{CH}$ hexagonal crystals, these phases are not uniformly distributed through the hardened cement matrix; in addition, capillary micro pores are obvious. The inclusion of GGBS has remarkably improved the microstructure, denser and compact microstructure has been observed; furthermore, $\mathrm{CH}$ big crystals are absent; instead, gel-like CSH is predominant because of the pozzolanic reaction as shown in fig.5b. Fig.6a shows a $\mathrm{FeCr}$ aggregate embedded within the cement matrix the EDAX confirm the growth of $\mathrm{CSH}$ over $\mathrm{FeCr}$ aggregate surface; although, good binding is evident between aggregate and hydrated cement, big voids are present owing to the relatively less packing. The use of GGBS resulted in the production of additional honeycomb-shaped CSH networks in the inter-particle space and relatively improves the packing efficiency as depicted in fig.6b and confirmed by EDAX analysis. 

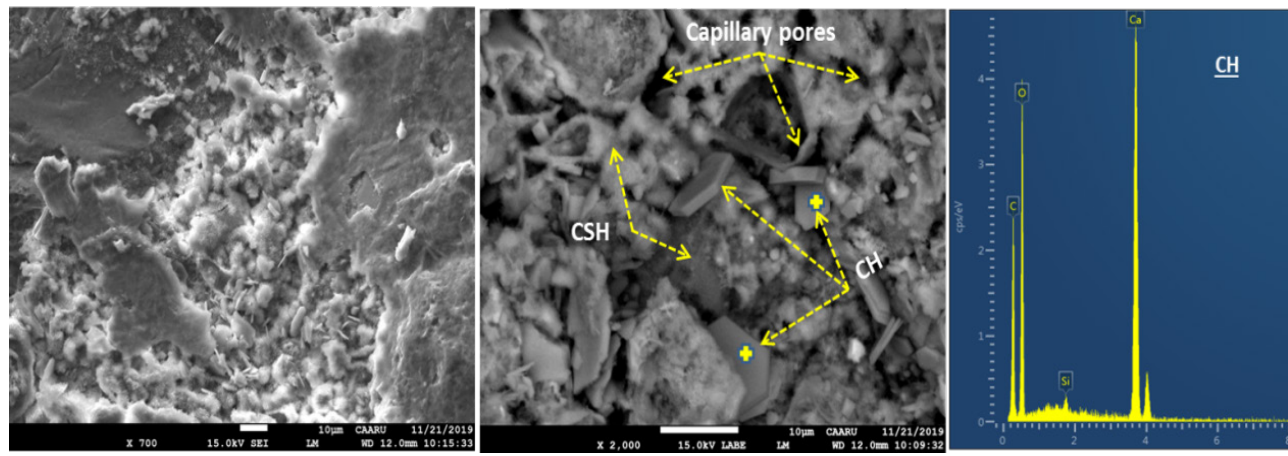

(a)
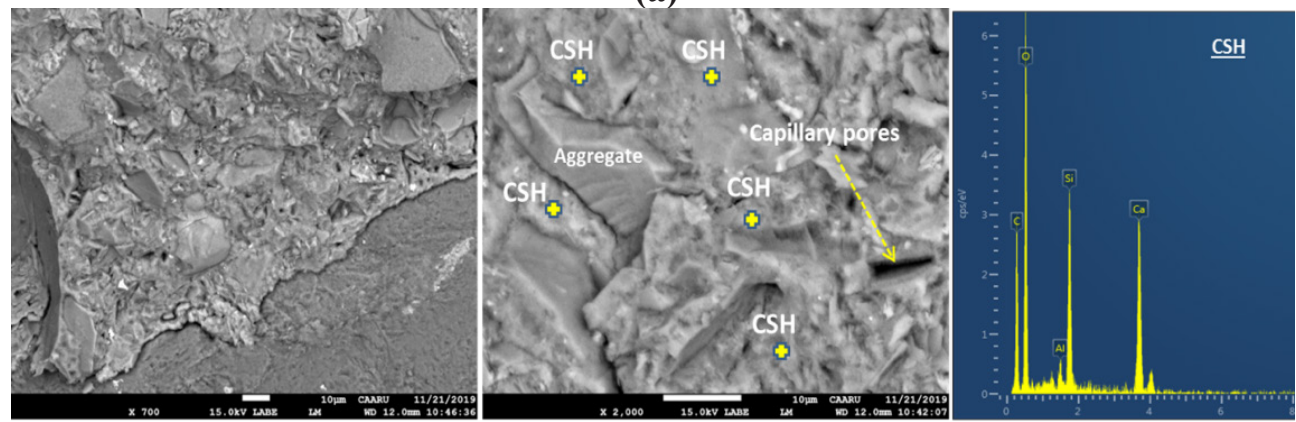

(b)

Figure 5: SEM micrographs and EDAX spectra of selected areas for mortars containing 0 wt.\% FeCr made of (a) OPC and (b) GGBS-blended OPC
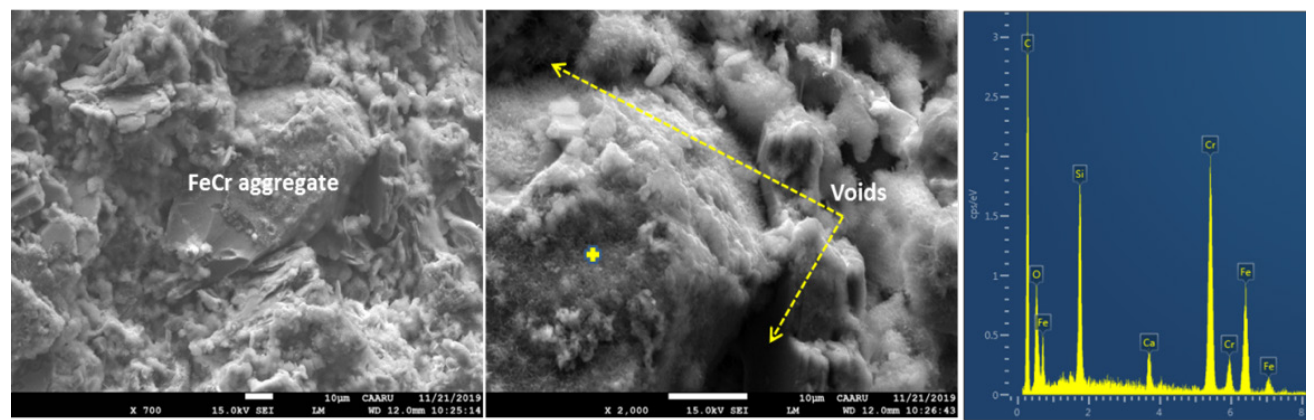

(a)
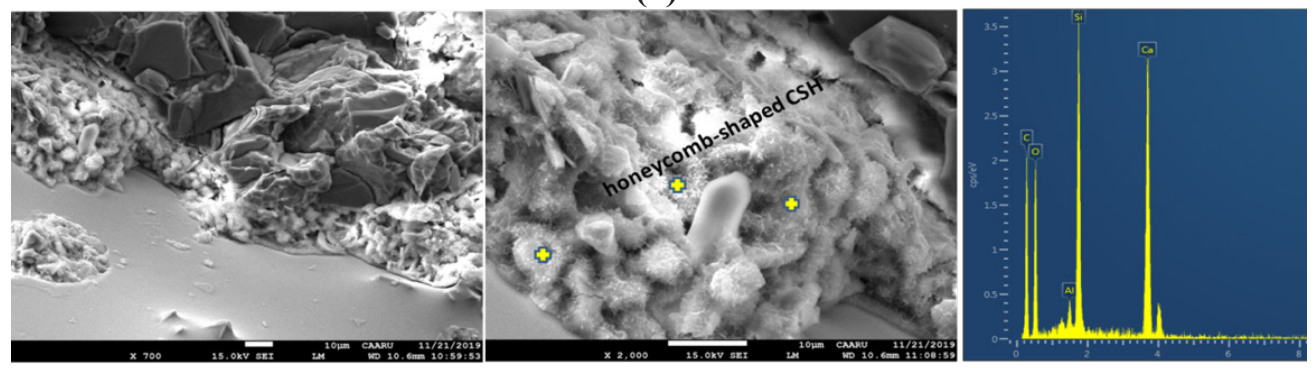

(b)

Figure 6: SEM micrographs and EDAX spectra of selected areas for mortars containing 25 wt.\% FeCr made of (a) OPC and (b) GGBS-blended OPC 


\section{CONCLUSION}

The combined/hybrid effects of $\mathrm{FeCr}$ slag together with GGBS on compressive strength, permeable voids content, thermal conductivity and microstructure of cement mortar have been investigated. The experimental results of this study warranted the following conclusions:

- The $\mathrm{FeCr}$ slag has a potential to be used as a substitute for fine natural sand in cement-based construction materials.

- The grading characteristics of $\mathrm{FeCr}$ fine aggregates affect to a great extent the mechanical strength and thermo-physical properties of mortar and play important role in determining the optimum replacement levels for natural sand. The inadequate gradation of the as received $\mathrm{FeCr}$ slag samples has restricted its utilization as sand replacement at higher percentages more than $25 \%$.

- Controlling the grain size distribution of $\mathrm{FeCr}$ slag could help in improving the strength of the mortars incorporating high percentages of $\mathrm{FeCr}$ slag.

- The use of SCMs like GGBS is very helpful in enhancing strength, reducing voids content and improving microstructure of the $\mathrm{FeCr}$-slag blended mortars.

- The use of $\mathrm{FeCr}$ slag at percentages higher than $25 \%$ reduces compressive strength and thermal conductivity, this may recommend these mortars (containing high amount of $\mathrm{FeCr}$ ) for plastering applications where the high strength is not an important factor; however, the reduced thermal conductivity is useful for reducing heat transfer by conduction and hence improving thermal performance of exterior walls of buildings especially in hot weather regions.

\section{ACKNOWLEDGEMENT}

The authors would like to acknowledge the financial support provided by Sohar Port and Free Zone Company under Sultan Qaboos University Grant No. CR/ENG/ CAED/18/07.

\section{REFERENCES}

Al-Jabri, K. S., Hisada, M., Al-Oraimi, S. K. \& Al-Saidy, A.H. (2009). Copper slag as sand replacement for high performance concrete. Cement and Concrete Composites, 31(7), pp. 483-488.

Al-Jabri, K. S., Al-Saidy, A. H. \& Taha, R. (2011). Effect of copper slag as a fine aggregate on the properties of cement mortars and concrete. Construction and Building Materials, 25(2), pp.933-938.

Al-Jabri, K., Shoukry, H., Khalil, I. S., Nasir, S. \& Hassan, H. F. (2018a). Reuse of Waste Ferrochrome Slag in the Production of Mortar with Improved Thermal and Mechanical Performance. Journal of Materials in Civil Engineering, 30(8), p.04018152.

Al-Jabri, K. \& Shoukry, H. (2018b). Influence of nano metakaolin on thermo-physical, mechanical and microstructural properties of high-volume ferrochrome slag mortar. Construction and Building Materials, 177, pp. 210-221.

Babu, K. G. \& Kumar, V. S. R. (2000). Efficiency of GGBS in concrete. Cement and Concrete Research, 30(7), pp.1031-1036.

Borhan, T. M. (2012). Properties of glass concrete reinforced with short basalt fiber. Materials \& 
Design, 42, pp. 265-271.

Gori, F. \& Corasaniti, S. (2014). Effective thermal conductivity of composites. International Journal of Heat and Mass Transfer, 77, pp. 653-661.

Krishnamoorthy, R. R. \& Zujip, J. A. (2013). Thermal conductivity and microstructure of concrete using recycle glass as a fine aggregate replacement. International Journal of Emerging Technology and Advanced Engineering, 3(8), pp. 463-471.

Nadeem, M. \& Pofale, A. D. (2012). Replacement of natural fine aggregate with Granular Slag-A waste industrial by-product in cement mortar applications as alternative construction materials. International Journal of Engineering Research and Applications, 2(5), pp. 12581264.

Niemelä, P. \& Kauppi, M. (2007). Production, characteristics and use of ferrochromium slags. INFACON XI, pp. 171-179.

Oner, A. \& Akyuz, S. (2007). An experimental study on optimum usage of GGBS for the compressive strength of concrete. Cement and Concrete Composites, 29(6), pp. 505-514.

Rao, G. A. \& Prasad, B. R. (2002). Influence of the roughness of aggregate surface on the interface bond strength. Cement and Concrete Research, 32(2), pp. 253-257.

Saha, A. K. \& Sarker, P. K. (2017). Compressive strength of mortar containing ferronickel slag as replacement of natural sand. Procedia engineering, 171, pp. 689-694.

Saha, A. K., Sarker, P. K. \& Majhi, S. (2019). Effect of elevated temperatures on concrete incorporating ferronickel slag as fine aggregate. Fire and Materials, 43(1), pp. 8-21.

Sikora, P., Horszczaruk, E., Skoczylas, K. \& Rucinska, T. (2017). Thermal properties of cement mortars containing waste glass aggregate and nanosilica. Procedia engineering, 196, pp. 159166.

Taha, B. \& Nounu, G. (2008). Properties of concrete contains mixed color waste recycled glass as sand and cement replacement. Construction and Building Materials, 22(5), pp. 713-720.

Cite this article as: Baawain M., Shoukry H., Al-Jabri K., "Mechanical Performance and Thermo- 